\title{
In Memoriam: Prof. Varanasi Sitaramaiah
}

$$
\text { (20 January } 1952-2 \text { October 2020) }
$$

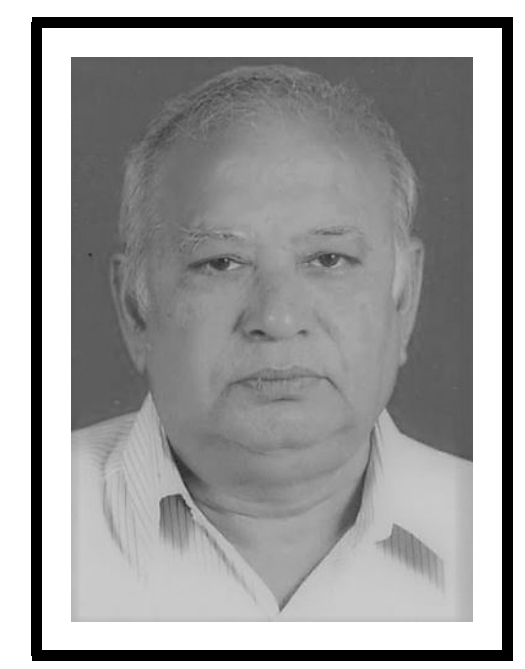

On 2 October 2020, the great Indian mathematician, Professor Varanasi Sitaramaiah, passed away. He was a passionate mathematician, enthusiastic about pure mathematics, and a modest humanbeing.

His main interest was focused on Number Theory, especially on arithmetic functions. He contributed substantial results, among others, to Narkiewicz's regular convolution, Lehmer's psi-convolution, unitary analogs and asymptotics.

His last passion was the intensive study of bi-unitary multiperfect numbers, working with these numbers all the way. He published these last results in our journal.

We wish to pay tribute to the memory of this great mathematician.

The Editorial Board of "Notes on Number Theory and Discrete Mathematics" 